This is an author produced version of a paper published in Science.

This paper has been peer-reviewed and is proof-corrected, but does not include the journal pagination.

Citation for the published paper:

David A. Wardle, Richard D.Bardgett, Ragan M. Callaway and Wim H. Van der Putten. (2011) Terrestrial Ecosystem Responses to Species Gains and Losses. Science. Volume: 332, pp 1273-1277. http://dx.doi.org/10.1126/science.1197479

Access to the published version may require journal subscription. Published with permission from: American Association for the Advancement of Science.

Standard set statement from the publisher:

Authors of research articles, reports, brevia, reviews, or technical comments created under grants awarded no earlier than 2 May 2005 who are required by their funding agencies to make their research results publicly available may implement posting to the funding body's archive or designated repository, no sooner than six months after final publication, of the "accepted version" of the paper, provided the posting is linked back to the original AAAS published version and includes the published paper's full reference citation. The "accepted version" is the version of the paper accepted for publication by AAAS after changes resulting from peer review, but before AAAS's editing, image quality control, and production. This policy does not apply to categories of papers other than those identified above. In submitting to archives such as PMC, authors should set the time of public release of the accepted version at six months after final publication by AAAS.

Epsilon Open Archive http://epsilon.slu.se 


\section{Terrestrial Ecosystem Responses to Species Gains and Losses}

\section{David A. Wardle ${ }^{1^{*}}$, Richard D. Bardgett ${ }^{2}$, Ragan M. Callaway ${ }^{3}$, and Wim H. Van der Putten ${ }^{4}$}

${ }^{1}$ Department of Forest Vegetation Ecology, Faculty of Forestry, Swedish University of Agricultural Sciences, SE901-83 Umeå, Sweden

${ }^{2}$ Soil and Ecosystem Ecology Laboratory, Lancaster Environment Centre, Lancaster University, Lancaster LA1 4YQ, UK.

${ }^{3}$ Division of Biological Sciences, The University of Montana, Missoula, MT 59812, U.S.A.

${ }^{4}$ Department of Terrestrial Ecology, Netherlands Institute of Ecology NIOO-KNAW, P.O. Box 50, 6700 AB Wageningen, The Netherlands and Department of Nematology, Wageningen University, Wageningen, The Netherlands.

* Corresponding Author: David Wardle

Fax: (46)(90)786-6612

Ph: (46)(90)786-6981

E-mail: david.wardle@svek.slu.se 
1 (Abstract) Ecosystems worldwide are losing some species and gaining others, resulting in an

2 interchange of species that is having profound impacts on how these ecosystems function.

3 However, research on the effects of species gains and losses has developed largely independently

4 of one another. Recent conceptual advances regarding effects of species gain have arisen from

5 studies that have unravelled the mechanistic basis of how invading species with novel traits alter

6 biotic interactions and ecosystem processes. In contrast, studies on traits associated with species

7 loss are fewer, and much remains unknown about how traits that predispose species to extinction

8 affect ecological processes. Species gains and losses are both consequences and drivers of global

9 change, thus explicit integration of research on how both processes simultaneously affect

10 ecosystem functioning is key to determining the response of the Earth system to current and future

11 human activities.

12

13

14

15 Human-induced global change is causing ecological communities to rapidly lose some species and

16 gain others, resulting in interchanges of species, their traits and interactions, and alteration of

17 ecosystem functioning and services. Significant losses of species at both global and local scales

18 have occurred as a consequence of human-induced factors (1), and are expected to continue well

19 into this century $(2,3)$. Human migration and global change have also facilitated the spread of a

20 vast range of organisms into new habitats, leading to biological invasions of many communities,

21 and often homogenization of species among them (4). As local-scale losses of native species and

22 ingress of new species occur simultaneously, both net gains and losses of species richness are

23 occurring $(5,6)$. While the Earth is experiencing substantial losses of biodiversity at the global 
1 level (1), both increases and decreases in community diversity are commonly observed at regional

2 and local scales (5).

This type of interchange of biota is highly relevant to the growing interest in the role that

$4 \quad$ species attributes have in driving terrestrial ecosystem processes, both aboveground and belowground $(6,7)$. Species losses have their greatest effect when the lost species were previously abundant and/or had functionally irreplaceable roles. Further, the effects of new or invasive species are likely to be greatest when they possess functionally novel attributes that the native species lack and/or become abundant in the recipient ecosystem. Despite gains and losses of species at local scales being comparable processes (Fig. 1), the literature on the effects of species gains on ecosystem properties has largely developed independently to that on the effects of species losses.

11 In this review we bring these two issues together to develop insights into how ongoing and simultaneous gains and losses of species in terrestrial communities can cause shifts in the distribution of traits in the biota, thereby radically altering the functioning of terrestrial ecosystems.

\section{Species Gain - Invasion and Range Expansion}

Species gain is derived from colonization and establishment of new species; processes that are increasing in frequency and intensity at global scales via cross-continental introductions, land use change and climate warming, with demonstrated effects at the ecosystem level (Fig. 2). For plants, the development of viable populations of new species and their spread can occur rapidly as they pass through the stages of the invasion process. The impact of these species on community dynamics and ecosystem function is increasingly recognized as being correlated with the novelty of their traits relative to those of natives $(8,9)$. Recent studies have explored such novelty through phylogenetic relationships (9), secondary biochemistry (8), and allocation of carbon and nutrients

24 (10). For example, a comparison in eastern Australia of leaf traits for 75 native and 90 exotic 
1 invasive plant species (11) showed that the invasives had significantly higher nitrogen and

2 phosphorus concentrations, assimilation rates, and leaf area ratios than did the natives. As such,

3 when invasive plants become disproportionally dominant over time, these traits can have profound

4 effects on ecosystem properties including local increases of nutrient stocks, rates of nutrient

5 cycling and primary productivity (10), although there are many exceptions (12) (Fig. 3).

Recent studies have shown that novel traits of invasive plants can undergo rapid evolution,

$7 \quad$ which may either diminish (13) or increase (14) the impacts of the invaders on invaded ecosystems

8 over time. We now also know that over time exotic plants can be subjected to increasing regulation

9 by their enemies, which may be due to evolutionary responses of competitors or enemies that are

10 native to the invaded range (15). As such, while community and ecosystem impacts of invasive

11 plants may be initially strong due to their novel traits and strengthen through selection, they may not be sustained in the longer term as decomposers, herbivores and pathogens in the invaded range

13 adapt (13). This dynamic process can be affected by the limited genetic variability of some

14 invaders, which may impede evolutionary responses to biotic selection. Thus, exotic invaders may not necessarily derive longer-term benefits from aboveground and belowground enemy release or 16 interactions with mutualistic symbionts (16).

Several recent studies have shown that gains in invasive consumers can transform ecosystems (Fig. 2), especially when host species that are poorly adapted to the invader are also ecosystem drivers (6). As such, large shifts in vegetation composition and aboveground and belowground processes may result from the invasion of functionally novel species of vertebrate

21 and invertebrate herbivores (17), root pathogens (18) and earthworms (19) (Fig. 2). Strong ecosystem effects may result especially when invasive consumers introduce a novel disturbance;

23 for example, recent widespread clearance of riparian Nothofagus forest in southern South America by exotic beavers is thought to be the largest landscape-scale disturbance in these forests since the 
1 last ice age (20). Invasive predators also have cascading effects on ecosystem processes when they

2 extirpate prey that itself has a key ecological role. For example, predation on seabirds by invasive

3 foxes on the Aleutian Islands (21) and rats on offshore New Zealand islands (22), radically

4 transform several ecosystem properties through thwarting nutrient transfer by seabirds from the

5 ocean to land. Despite the growing number of spectacular examples of how invasive consumers

6 transform ecosystems (Fig. 2), relatively few general principles exist regarding what organism

7 traits lead to new species of consumers becoming invasive (23), and even less is known about

8 when and how these traits may transform ecosystem processes.

$9 \quad$ Global changes may promote (24) or limit (25) range expansions of plants and animals.

10 Range expanding organisms and their enemies probably move at different rates (26), thus range

11 expansion can result in disruption of both aboveground and belowground trophic interactions. Even

12 when both prey and predator species expand their range at the same rate, the original trophic

13 interactions may not necessarily become re-united in the new range (27), which may make range

14 expanders behave as invaders (28). Aboveground and belowground defense traits of latitudinal

15 range-expanding plant species can be more comparable to those of cross-continental exotic

16 invaders than of native congeneric species (28). In climate envelope models, potential latitudinal

17 range expansions are estimated with climate-distribution correlations (25). Including aboveground

18 and belowground biotic interactions in those analyses and their different response rates to global

19 environmental changes could reveal why some species do better and others worse than compared to

20 model predictions. In spite of the many studies on climate warming effects on ecosystem processes,

21 little attention has been given to ecosystem-level consequences of species gain due to range

22 expansions or species loss due to range contractions.

23

24 Species Loss - Extinction and Range Contraction 
1 Mechanistic understanding of how plant species gains affect community and ecosystem properties

2 at local scales is accelerating, but knowledge of the effects of plant species losses at comparable

3 scales remains more limited. Most work on impacts of species loss has been in the context of

4 'biodiversity and ecosystem functioning' studies, where species richness is experimentally varied

5 (often through random draws from a species pool) to infer how species loss in real ecosystems

6 influences ecological processes $(29,30)$. Such studies have enhanced our understanding of how

7 species, functional group, genetic or trait diversity influences ecological processes. However their

8 relevance for understanding species loss effects in real ecosystems continues to be debated (6, 29,

9 31, 32), in part because species are not lost from ecosystems at random and because small-scale

10 effects of species loss may not be manifest at larger scales. There is growing recognition that an

11 improved understanding of how biodiversity loss affects aboveground and belowground ecological

12 processes requires explicit recognition of the non-random nature of species loss, although there are

13 still few direct empirical tests of this $(33,34)$.

14 One way forward for developing general principles about how plant species loss affects real

15 ecosystems would be to take lessons from the improved understanding of invasive plant effects

16 generated by a focus on traits associated with the invaders. This would involve determination of

17 which traits predispose species to be lost from communities due to anthropogenic impacts, and

18 whether they are related to those traits that drive ecological processes (6, 31) (Fig. 3). For example,

19 nitrogen enrichment often causes losses of slow-growing plant species with traits associated with

20 poor resource quality that impair decomposer biota, in part because they provide litter of poorer

21 quality. Recent manipulation experiments $(35,36)$ show that species disadvantaged by nitrogen

enrichment have different interactions with the belowground subsystem than those that benefit. As

23 another example, effects of non-random removal of particular forest tree species through selective

24 harvesting on aboveground and belowground properties depend upon the characteristics of species 
1 that are lost (37). Such examples provide models for exploring ecosystem impacts of other

2 anthropogenic species-loss scenarios. If species with particular traits that drive ecosystem

3 processes are disproportionately (as opposed to randomly) lost from communities, then

4 consequences for ecosystem functioning may be even greater than many biodiversity - ecosystem

5 function experiments would predict.

The link between species traits and extinction susceptibility has attracted some attention for

7 vertebrates. Mammals with slow growth rates, large body size and high trophic position are

8 disproportionately susceptible to both local and global extinction (38), and these traits may greatly

9 affect ecosystem processes. Losses of mega-herbivore species from major land masses worldwide

10 have caused major switches in vegetation, for example from productive fertile steppe to infertile

11 tundra in northern Russia (39). Further, reintroduction of locally extinct bison into tallgrass prairies

12 in North America has revealed the dramatic effects of their historical loss on soil biogeochemical

13 processes (40). Losses of cougars and wolves in much of North America may have caused

14 overabundance of cervid prey, with cascading effects on vegetation, watershed hydrology (41), and

soil fertility (42). Further, loss of seed-dispersing mammal species to poaching in national parks of

16 Thailand has impaired tree seed dispersal and seedling demographics, with likely ecosystem-level

17 impacts (43). Conversely, there are fewer examples of human-induced losses of small bodied

18 species affecting ecosystem processes (44), but it is unclear whether such species are less

19 important, or if the effect of their loss is more likely to go unnoticed (6).

Losses of biodiversity also occur at subspecific or genetic levels, but the ecological

21 consequences of these have been infrequently studied and mostly for plants. Whereas plant species

22 gains can result in establishment of large populations with limited genetic variation, plant species

23 losses can be preceded by progressive reduction of genetic variation, with considerable

24 implications for associated aboveground and belowground biota, and ecosystem functioning (45). 
1 In a recent meta-analysis, plant genetic variation was shown to have greater aboveground than

2 belowground effects, with larger impacts on consumer invertebrates of lower trophic status (46). In

3 partial agreement with this, genotypic variation in tall goldenrod (Solidago altissima) was found to

4 influence the diversity and abundance of leaf-feeding arthropods and their predators, whereas

5 effects on litter-feeding arthropods across multiple trophic levels were minimal (47). There is also

6 emerging evidence that plant genetic variation may have ecosystem-level consequences by

7 affecting carbon and nitrogen cycling and resource quality for litter decomposers and foliar

8 herbivores (48). Advances in understanding consequences of lost genetic variation will require

9 approaches that operate at the interface of community genetics, biotic interactions and ecosystem 10 processes.

11

12 Understanding Consequences Within and Among Ecosystems

13 Most studies have considered the ecosystem impacts of species gains and losses in isolation from

14 each other, despite both processes frequently occurring simultaneously within communities (49),

15 and not necessarily independently. For example, invasive predators may drive ecosystem processes

16 through causing the local extinction of their prey $(21,22)$. Further, loss of native plant species

17 potentially contributes to greater success of invasive species, although the importance of this in

18 natural ecosystems and the underlying mechanisms involved remains far from resolved (50).

19 Whenever species gains and losses occur in the same community, we have limited knowledge

20 about what the net consequences are for community and ecosystem processes. This is because we

21 have scant understanding of the temporal dynamics of species loss relative to species gain in the

22 community (49), and of whether those species that are lost from communities have comparable

23 functional characteristics to those that are gained (6). Understanding the impact of global change

24 on terrestrial ecosystem processes will require explicit focus on the trait spectra of those species 
1 that are both lost and gained as well as their interactions with other trophic level biota, and how

2 any net shift in these properties over time may impact on ecosystem functioning.

In addition to species gains and losses occurring simultaneously, there is mounting

evidence that the magnitude of effects of both processes on ecosystem functioning can vary depending on environmental conditions. For example, effects of plant diversity on primary productivity depend on soil fertility (51), as does the impact of mycorrhizal fungal diversity on host plant growth (52). Likewise, removal experiments in Boreal forests reveal that the impacts on belowground processes of the loss of understory species depends on soil fertility and ecosystem productivity (53). Further, the effects of the exclusion or invasion of large herbivores on ecosystem properties can vary depending on topography, geologic substrate, soil fertility and climate $(54,55)$.

11 Similarly, impacts of shrub invasion - which is occurring in arid and semi-arid grasslands worldwide - on primary production and soil biogeochemistry vary with climatic conditions (56).

Such context dependency calls for an improved understanding of how the balance between species gain and loss may be affected by environmental conditions and how the resulting net shifts in trait spectra may determine ecosystem properties.

Although few studies have explicitly addressed how climate change may accelerate modification of terrestrial ecosystems through species interchange, the widespread climatemediated expansion of many organisms $(24,57)$ has implications for local-scale ecosystem properties and potentially the Earth system. For example, pan-arctic shrub encroachment is predicted to retard decomposition rates due to production of poorer quality leaf and woody litter

21 than that of the species that are replaced (58). This may dampen atmospheric $\mathrm{CO}_{2}$ inputs caused by warming effects on organic matter decomposition and carbon loss from arctic soils (59). Also,

23 climate-mediated expansion of the mountain pine beetle (Dendroctonus ponderosae) may convert forests from being net carbon sinks to net sources, thereby reducing their capacity to offset 
1 anthropogenic $\mathrm{CO}_{2}$ emissions (60). Further, climate-mediated range expansion of large herbivores

2 (61) can result in shifts in vegetation composition and net ecosystem carbon exchange (6), and

3 modulate climate change effects on vegetation, for instance by constraining woody plant expansion

4 in response to warming (62). Research is needed to better understand the potential for species range

5 expansion to modulate ecosystem functioning under global change, and to unravel the relative

6 importance of factors that determine the scale of these impacts. In addition, comparisons of the

7 relative importance of the characteristics of the shifting species and the habitats into which they

8 expand, as well as the environmental changes that might cause range shifts, will allow us to better

9 target the drivers of range shifts.

Species gains and losses also have significant implications for the future management and

11 restoration of ecosystems. Restoration of ecosystems transformed by invaders not only requires an understanding of how the ecosystem functioning has been modified but also how reversible these

13 effects are if the invader is removed $(63,64)$. This requires consideration of whether the loss of 14 associated biota, including soil organisms, may limit subsequent restoration of native communities 15 and their capacity to deliver ecosystem functions. Restoration is also required to counteract species

16 loss, for example of plant species in grasslands subject to nutrient enrichment. Restoration of plant 17 diversity in such situations is primarily constrained by high soil fertility, seed limitation of later18 successional target species (65), and degraded soil communities (66). As a consequence, more 19 integrated aboveground-belowground interventions are needed to facilitate restoration of plant 20 diversity, including situations where some species have been lost while others have invaded (63), 21 and to potentially enhance delivery of ecosystem services such as carbon sequestration (67). 
1 The functioning of many ecosystems worldwide has been transformed, sometimes spectacularly,

2 by the losses of some species and the gains of others. However, our ability to generalize about or

3 predict when and how interchange of biota alters ecosystem properties is incomplete. There have

4 been recent advances in understanding how invasive plant species alter aboveground and

5 belowground properties. However, we need to better understand why most alien species do not

6 become invasive and whether the most invasive alien species are also those with novel attributes

7 that transform ecosystems (68). Despite many examples of major alterations of ecosystems by

8 invasive consumers (Fig. 2), we have yet to move from a collection of impressive examples to the

9 development of general principles about how, when and where alien consumer species may exert

10 such effects. Our ability to generalize about the impacts of species losses in real ecosystems

11 requires more experimental studies that include realistic and non-random species loss scenarios, as

12 well as the environmental factors that drive species losses. Crucially, while species gains and losses

13 occur simultaneously in many communities, we still have a dearth of knowledge about the net

14 consequences of the two processes occurring in tandem for terrestrial ecosystems functioning. As

15 such, the advancement of this topic will require studies that explicitly consider both species

16 invasion and extinction, as well as their interactions, environmental drivers and temporal dynamics.

17 To advance understanding of ecosystem impacts of species gains and losses either

18 separately or in combination, we highlight three areas that deserve attention. First, a trait-based

19 framework analogous to current 'effect trait' and 'response trait' frameworks $(26,69)$ has much to

20 offer. This could focus on whether those traits that predispose species to alter ecosystems are also

21 associated with invasiveness or extinction (Fig. 3). Second, greater attention is needed on whether

22 effects of species gains or losses on ecosystem properties are mostly a consequence of their relative

23 abundance or biomass (70), or if gains of subordinate species (71) or losses of rare species (34) are

24 also important. Third, despite growing evidence that effects of species gains and losses on 
1 ecosystem properties vary greatly among ecosystems, we lack understanding of what underpins

2 this context-dependency. Experimental and observational studies that investigate the impacts of

3 species gains and losses across contrasting ecosystems and environmental gradients could assist

4 our knowledge about how interchange of species and abiotic factors interact to drive ecosystem

5 properties. Further, since there are conceptual similarities between how gains and losses affect

6 ecosystems (Fig. 1), approaches used to study one can generate new insights into the other.

$7 \quad$ Improved understanding of the ecosystem consequences of interchange of species will also

8 assist our ability to evaluate the future consequences of global environmental change. First,

9 predictions of range shift due to climate change, such as those obtained by climate envelop models,

10 are based largely on abiotic factors. However, biotic interactions can govern species abundance

11 following their range expansion (28) and potentially the climate envelope of species invading new

12 regions (72). Explicit recognition of the need to include biotic interactions in novel climate

13 envelope models is growing, and this will help more accurate prediction of species distributions

14 and ecosystem effects under global change scenarios (73). Second, large scale transformations of

15 ecosystems following species gains or losses may have important, though largely unrealized

16 consequences for ecosystem carbon fluxes (74) that feed back to the Earth climate system (6).

17 Gains and losses of species from ecosystems are both a consequence and driver of global change,

18 and understanding the net consequences of this interchange for ecosystem functioning is key to

19 determining the response of the Earth system to current and future human activities. 


\section{References and Notes}

1. Millennium Ecosystem Assessment, Ecosystems and Human Well-Being (Island Press, Washington, D. C., 2005).

2. M. Hoffmann, et al., Science 330, 1496 (2010).

3. H.M. Pereira, et al., Science 330, 1503 (2010).

4. D. Simberloff, M. Rejmánek, Eds., Encyclopedia of Invasive Introduced Species (University of California Press, Berkeley, 2011).

5. D.F. Sax, S.D. Gaines, Trends Ecol. Evol. 18, 551 (2003).

6. R.D. Bardgett, D.A. Wardle. Aboveground-Belowground Linkages: Biotic Interactions, Ecosystem Processes and Global Change (Oxford University Press, Oxford, 2010).

7. W.H. Van der Putten, et al. Oecologia 161, 1-14 (2009)

8. R.M. Callaway, W.M. Ridenour, Front. Ecol. Environ. 2, 436 (2004).

9. S.Y. Strauss, C.O. Webb, N. Salamin, Proc. Natl. Acad. Sci. U. S. A. 103, 5841 (2006).

10. C.Z. Liao et al., New Phyt. 177, 706 (2008).

11. M.R. Leishman, T. Haslehurst, A. Ares, Z. Baruch, New Phyt. 176, 635 (2007).

12. H. Kurokawa, D. Peltzer, D.A. Wardle, Funct. Ecol. 24, 513 (2010).

13. R.A. Lankau, V. Nuzzo, G. Spyreas, A.S. Davis, Proc. Natl. Acad. Sci. U. S. A. 106, 15362 (2009).

14. Z.L. Feng et al., Ecosystems 12, 534 (2009).

15. J.M. Diez et al., Ecol. Lett. 13, 803 (2010).

16. S. Rodriguez-Echeverria, J.A. Crisostomo, C. Nabais, H. Freitas, Biol. Invasions 11, 651 (2009).

17. G.M. Lovett et al., BioScience 56, 395 (2006).

18. R. C. Venette, S. D. Cohen, For. Ecol. Manage. 231, 18 (2006).

19. P.J. Bohlen et al., Front. Ecol. Environ. 2, 427 (2004).

20. C.B. Anderson et al., Mammal Rev. 39, 33 (2009). 
21. J.L. Maron et al., Ecol. Monogr. 76, 3 (2006).

22. T. Fukami et al., Ecol. Lett. 9, 1299 (2006).

23. M. van Kleunen, W. Dawson, D. Schlaepfer, J. M. Jeschke, M. Fischer, Ecol. Lett. 13, 907 (2010),

24. G.R. Walther et al., Trends Ecol. Evol. 24, 686 (2009).

25. W. Thuiller, S. Lavorel, M.B. Araujo, M.T. Sykes, I.C. Prentice, Proc. Natl. Acad. Sci. U. S. A. 102, 8245 (2005).

26. M.P. Berg et al., Glob. Change Biol. 16, 587 (2010).

27. R. Menendez, A. Gonzalez-Megias, O.T. Lewis, M.R. Shaw, C.D. Thomas, Ecol. Entomol. 33, 413 (2008).

28. T. Engelkes et al., Nature 456, 946 (2008).

29. D.U. Hooper et al., Ecol. Monogr. 75, 3 (2005).

30. S. Naeem et al., Eds., Biodiversity, Ecosystem Functioning, and Human Wellbeing (Oxford University Press, Oxford, 2009).

31. J.E. Duffy, Front. Ecol. Env. 8, 437 (2009).

32. J. Leps, Basic Appl. Ecol., 5, 529-534.

33. J.R. McLaren, R. Turkington, J. Ecol. 98, 459 (2010).

34. E.S. Zavaleta, K.B. Hulvey, Science 306, 1175 (2004).

35. P. Manning et al., Ecol. Lett. 9, 1015 (2006).

36. K.N. Suding et al., Ecol. Monogr. 78, 313 (2008).

37. S. Díaz, A. Hector, D.A. Wardle, Curr. Opin. Environ. Sust. 1, 55 (2009).

38. A. Purvis, J.L. Gittleman, G. Cowlishaw, G. M. Mace, Proc. Roy. Soc. Lond. Ser. B 267, 1947 (2000)

39. S. Zimov, Science 308, 791 (2005).

40. A.K. Knapp et al., BioScience 49, 39 (1999). 
41. W.J. Ripple, T.P. Rooney, R.L. Betscha, in Trophic Cascades, J. Terborgh, J.A Estes, Eds.

(Island Press, Washington, D. C., 2010), pp. 141-162.

42. D.A. Frank, Oikos 117, 1718 (2008).

43. J.F. Brodie, O.E. Helmy, Y.Y. Brockelman, J.L. Maron, Ecol. Applic. 19, 854 (2009).

44. T. H. Larsen, N. M. Williams, C. Kremen, Ecol. Lett. 8, 538 (2005).

45. A.R. Hughes, B.D. Inouye, M.T.J. Johnson, N. Underwood, M. Vellend, Ecol. Lett. 11, 609 (2008).

46. J.K. Bailey et al., Philos. Trans. R. Soc. B-Biol. Sci. 364, 1607 (2009).

47. G.M. Crutsinger, W.N. Reynolds, A.T. Classen, N.J. Sanders, Oecologia 158, 65 (2008).

48. A.T. Classen, S.K. Chapman, T.G. Whitham, S.C. Hart, G.W. Koch, J. Ecol. 95, 1181 (2007).

49. S. T. Jackson, D. F. Sax, Trends Ecol. Evol. 25, 153 (2009).

50. J. D. Fridley, et al., Ecology 88, 3 (2007).

51. J.D. Fridley, Oecologia 132, 271 (2002).

52. L.M. Jonsson, M.-C. Nilsson, D.A. Wardle, O. Zackrisson, O. Oikos 93, 353 (2001).

53. D.A. Wardle, O. Zackrisson, Nature 435, 806 (2005).

54. D.J. Augustine, S.J. McNaughton. Ecosystems 9, 1242 (2006).

55. G.P. Anser, et al., Proc. Nat. Acad. Sci. USA 106, 4947 (2009).

56. F.T. Maestre, et al., Ecol. Lett. 12, 930 (2009).

57. J. Lenoir, J-C. Gégout, P. A. Marquet, P. de Ruffray and H. Brisse, Science 320, 1768 (2008).

58. E. Dorrepaal, J.H.C. Cornelissen, R. Aerts, B. Wallén, R.S.P Van Logtestijn, J. Ecol. 93, 817 (2005).

59. J.H.C. Cornelissen, et al., Ecol. Lett. 10, 619 (2007).

60. W.A. Kurz, et al., Nature 452, 987 (2008).

61. S. Sharma, S. Courtier, S.D. Côte, Global Change Biol. 15, 2549 (2009).

62. E. Post, C. Pedersen, Proc. Nat. Acad. Sci. USA 105, 12353 (2008). 
63. P. Kardol, D.A. Wardle, Trends Ecol. Evol. 25, 670 (2010).

64. S.G. Yelenik, J.M. Levine, Ecol. Appl. 20, 716 (2010).

65. R. S. Smith, et al., J. Appl. Ecol. 45, 670 (2008).

66. C. Hawkes, V. Eviner, Rest. Ecol. 16, 713 (2008).

67. G. B. De Deyn, et al., J. Appl. Ecol. (in press), DOI: 10.1111/j.1365-2664.2010.01925.x.

68. J. M. Levine, M. Vila, C. D'Antonio, J. S. Dukes, K. Grigulis, S. Lavorel, Proc. Roy. Soc. Ser. B, 270, 1517 (2003).

69. K. N. Suding et al., Glob. Change Biol. 14, 1125 (2008).

70. J. P. Grime, J. Ecol. 86, 902 (1998).

71. D. A. Peltzer, et al., Oikos 118, 1001 (2009).

72. R. V. Gallagher, L. J. Beaumont, L. Hughes, M. R. Leishman, J. Ecol. 98, 790 (2010).

73. S. Lavernge, N. Mouquet, W. Thuiller \& O. Ronce. Ann. Rev. Ecol. Evol. Syst. 41, 321 (2010).

74. D. A. Peltzer, R. B. Allen, G. M. Lovett, D. Whitehead, D. A. Wardle, Glob. Change Biol. 16, 732 (2010).

75. P. M. Vitousek, L. R. Walker, Ecol. Monogr. 59, 247 (1989).

We thank Tad Fukami, Fernando Maestre, Jason Tylianakis and anonymous reviewers for helpful comments, and Alice Bardgett and Kelley Gundale for help with figure preparation. DAW was supported by a Wallenberg Scholars award and WvdP by an ALW-Vici award 
FIGURE LEGENDS

Fig. 1. The sequence of events generally associated with species loss and gain over time, revealing conceptual parallels and differences between the two processes.

Fig. 2. Invasive organisms occupying any trophic position can radically transform ecosystems when they introduce novel traits to the ecosystem. (A) Invasion of Brazilian cerrado (left) by Pinus elliotii and elimination of native species (right). (B) Invasion front in grassland in Patagonia (Chile) of Pinus contorta which produces acidic litter that alters soil communities and impairs decomposer processes; (C) Invasive fallow deer (Dama dama) effects in northern New Zealand; on the left removal by deer of palatable shrubs with high litter quality leads to domination of the ground layer by low litter quality grasses and alterations of soil food webs; (D) Dieback of Australian Eucalyptus forest caused by the invasive root fungal pathogen Phytophthora cinnamoni; (E) Extensive felling of Nothofagus antarctica forest following invasion by North American beavers (Castor canadensis) in southern Chile; (F) Removal of forest understory and litter by nesting seabirds on offshore New Zealand islands (left) is mitigated by invasive rat (Rattus) species that consume seabird eggs and chicks (right); (G) Dense understory in Acer saccharum forest in Wisconsin (left) is greatly reduced following invasion by the burrowing earthworm Lumbricus terrestris (right); $(\mathrm{H})$ Waterlogging and vegetation change in southern Scotland resulting from removal of burrowing flatworms by the invasive predatory New Zealand flatworm (Aryhurdendyus triangulata). Photo credits: (A) R. Callaway; (B) M. Gundale, (C) D. Wardle, (D) Dieback Working Group, (E) C. Anderson; (F) (left) D. Wardle, (right) T. Fukami; (G) P. Ojanen; (H) B. Boag.

Fig. 3. Role of species traits in determining how gains of exotic species within trophic levels may affect ecosystem processes. (A) Different relationships at the whole community level between the 
functional significance of traits for ecosystem processes, and (standardized) biomass-weighted differences in trait values between native and exotic species, with each cross representing a different trait. (a) Situations in which those traits that differ between invasive and native species are the functionally most important, such as when $\mathrm{N}$ fixing plants invade ecosystems lacking $\mathrm{N}$ fixers (75), or beavers invade ecosystems lacking functionally equivalent herbivores (20). (b) Cases where traits that drive ecosystem processes are different than traits that differ between invasive and native species, such as for decomposition of litter from native and invasive species on New Zealand floodplains (12). (c) A situation that is intermediate between (a) and (b). The ecosystem effect of invasive species is also determined by whether they occupy a high proportion of community biomass within their trophic level, and (B) shows the effects of invaders on ecosystem processes as a function of their contribution to community biomass for the scenarios for each of (a) to (c), assuming that the relationship between relative invader biomass and its effects on processes is linear; other relationships are possible. The same approach could potentially be used for understanding the ecosystem effects of species losses, by considering traits of those species lost from the community relative to those that remain, although such an approach has seldom been considered (69) and would be more challenging to implement because this also requires historical knowledge of the proportion of community biomass that was previously occupied by the lost species. 


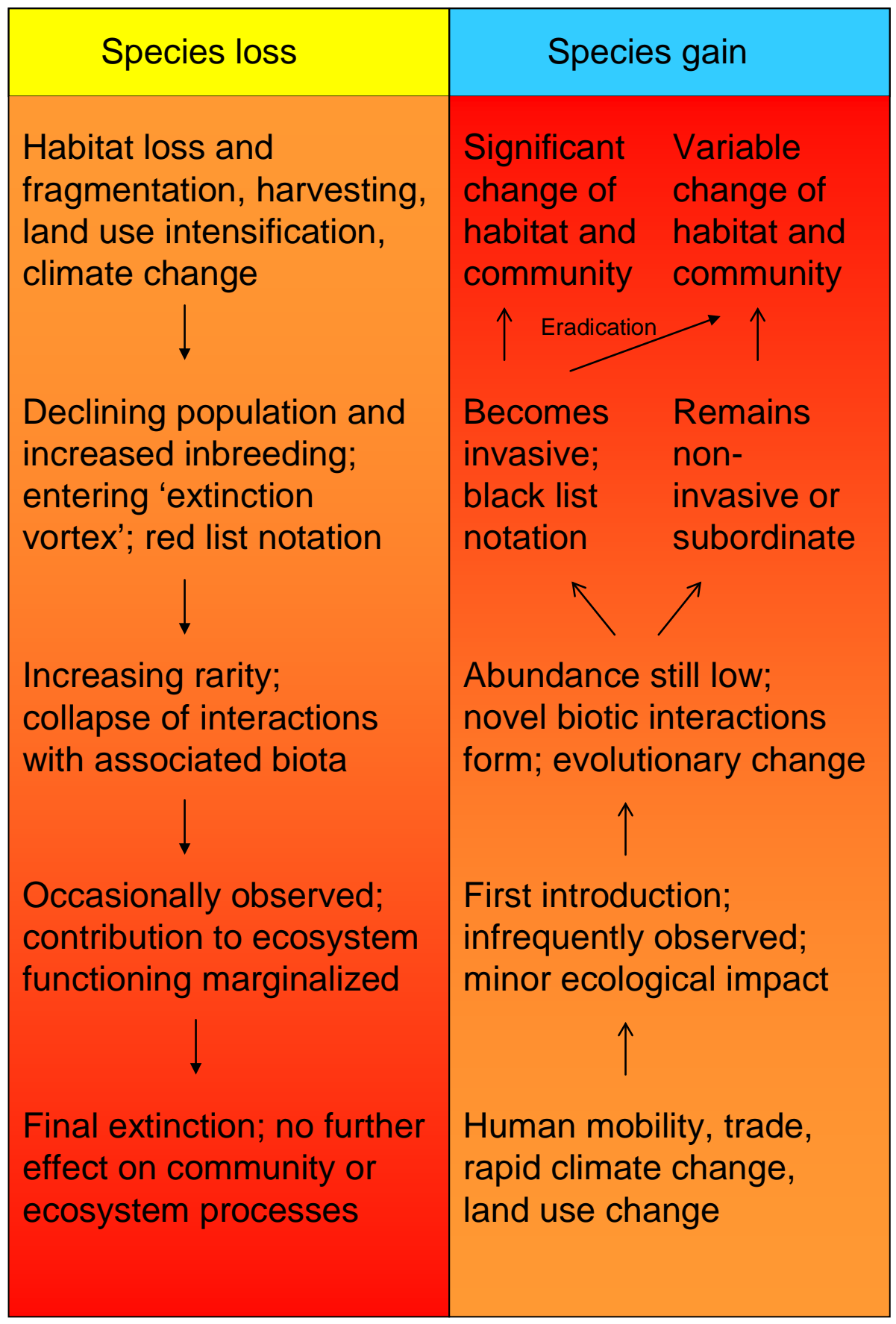

Fig. 1. 


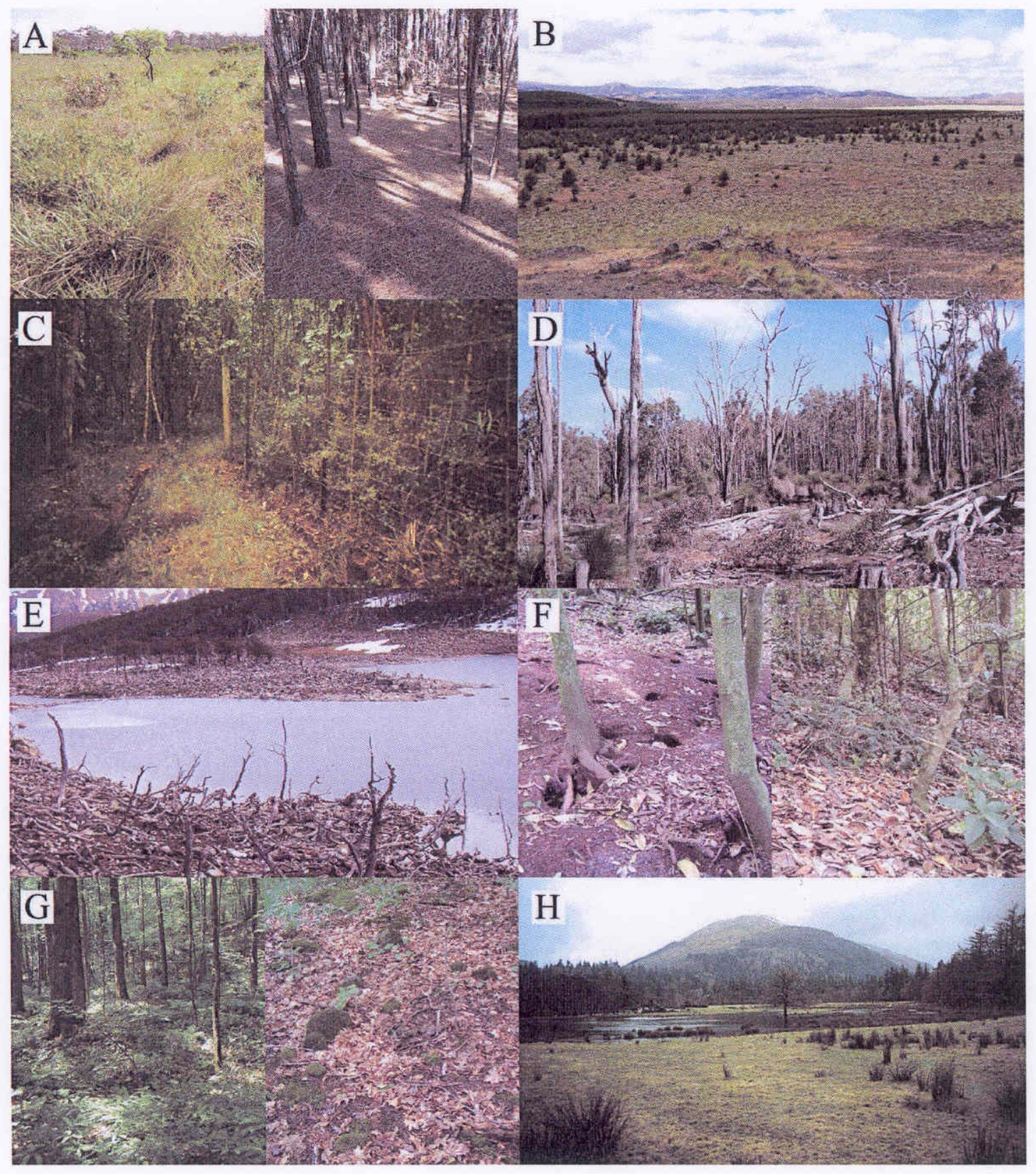

Fig. 2. 

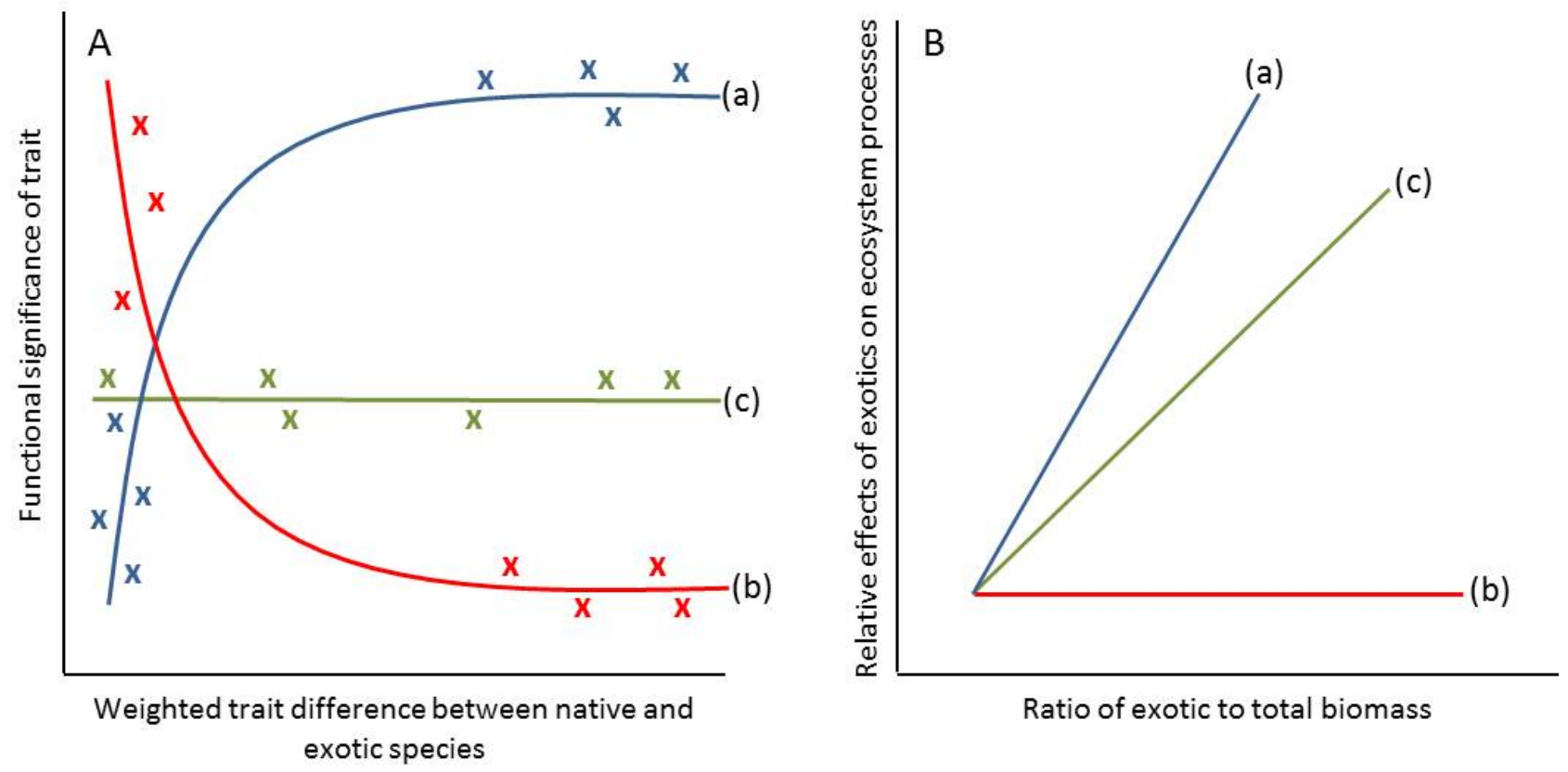

Fig. 3. 